\title{
Gender Gaps in Perceptions of Political Science Journals
}

\author{
Nadia E. Brown, Purdue University \\ Yusaku Horiuchi, Dartmouth College \\ Mala Htun, University of New Mexico \\ David Samuels, University of Minnesota
}

ABSTRACT The gender publication gap puts women at a disadvantage for tenure and promotion, which contributes to the discipline's leaky pipeline. Several studies published in $P S$ find no evidence of gender bias in the review process and instead suggest that submission pools are distorted by gender. To make a contribution to this important debate, we fielded an original survey to a sample of American Political Science Association members to measure participants' perceptions of political science journals. Results reveal that the gender submission gap is accompanied by a gender perception gap at some but not all political science journals we study. Women report that they are more likely to submit to and get published in some journals, whereas men report as such with regard to other journals. Importantly, these gaps are observed even among scholars with the same methodological (i.e., quantitative or qualitative) approach.

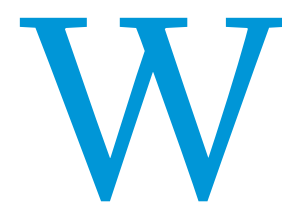
omen are underrepresented in the tables of contents of the political science profession's most prestigious journals (Breuning and Sanders 2007; Evans and Moulder 2011; Teele and Thelen 2017). Because men are more likely to publish in these journals, they gain greater visibility, which leads to gender gaps in citation patterns (Dion, Sumner, and Mitchell 2018; Maliniak, Powers, and Walter 2013) and underrepresentation of women on syllabi (Colgan 2017). As long as scholars are evaluated by the quantity of publications in prestigious journals, the gender publication gap puts women at a disadvantage for tenure and promotion (Box-Steffensmeier et al. 2015), which may contribute to the discipline's leaky pipeline.

Several recent studies published in PS examine potential sources of this gender publication gap but find no evidence of gender bias in the review process (Breuning et al. 2018; König and Ropers 2018; Nedal and Nexon 2018; Peterson 2018; Samuels 2018; Tudor and Yashar 2018). ${ }^{2}$ Instead, they find that submission pools are distorted by gender. Women, compared to men, comprise a far smaller

Nadia E. Brown is associate professor of political science and African American studies at Purdue University. She can be reached at brown957@purdue.edu. Yusaku Horiuchi iD is professor of government and the Mitsui professor of Japanese studies at Dartmouth College. He can be reached at yusaku.horiuchi@dartmouth.edu. Mala Htun iD is professor of political science at the University of New Mexico. She can be reached atmalahtun@unm.edu.

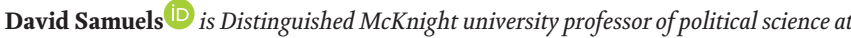
the University of Minnesota. He can be reached at dsamuels@umn.edu. share of authors submitting to most of the journals evaluated in their studies, and this submission gap starts among graduate students (Tudor and Yashar 2018).3 A large survey of political scientists' professional activities (Djupe, Smith, and Sokhey 2019) similarly affirms that men report submitting more papers than women, especially among assistant professors and scholars with quantitative approaches.

To contribute to this important debate, we fielded an original survey to a sample of American Political Science Association (APSA) members. Specifically, we asked participants whether they are likely to submit to and get published in each of 13 political science journals, including American Journal of Political Science (AJPS); American Political Science Review (APSR); Comparative Political Studies (CPS); International Organization (IO); Journal of Political Science Education (JPSE); Journal of Politics (JOP); Perspectives on Politics (PoP); Political Analysis (PA); Political Behavior (PB); Political Research Quarterly (PRQ); Political Theory $(P T)$; Politics, Groups, and Identities (PGI); and Polity.

Results reveal that the gender submission gap is accompanied by a gender perception gap at some but not all leading journals. Among journals with a gap, they run in both directions. Men state that they are more likely to submit work to and get published in some journals, such as APSR, AJPS, and PA. Women state that they are more likely to submit work to and get published in other journals, such as PGI. As this suggests, perception gaps do not always align with submission gaps. Existing studies show that submission gaps are consistent across journals, whereas the perception gaps that we find vary substantially. 
After describing the survey design and our results, we speculate about the reasons for the gender perception gaps we find. Our data permit us to rule out a common claim: a gender gap in methods. Our results reveal perception gaps even among scholars with the same methodological (i.e., quantitative or qualitative) approach. In the conclusion, we argue that the alignment-or lack thereof-of perception gaps and submission gaps should inform journal editors' outreach strategies.

\section{SURVEY DESIGN}

Are women more inclined than men to submit their manuscripts to some journals and less inclined to submit to others? Do women perceive the chances of publication differently than men? If so, to what extent can these differences be attributed to different methodological approaches? 4 To answer these questions, we invited a sample of 2,440 APSA members to participate in an online survey from October 10 to November 6, 2017.5 We received 810 completed surveys, for a response rate of $33.2 \%$. The journals included in our study are the two APSA flagship journals, APSR and PoP; each of the main journals of the major US regional political science associations, AJPS, JOP, Polity, and PRQ; and one important journal or two from different subfields of research and practice, $C P S, I O$, JPSE, PA, $P B, P G I$, and $P T$.

For each journal, we asked (displayed on the same page): "Thinking about [the name of a journal], what is... [t] he likelihood you will submit your work to this journal...[and t] he likelihood your work will be published in this journal?" Participants responded to these questions on five-point ordinal scales with the following response options: "very likely," "somewhat likely," "neither likely nor unlikely," "somewhat unlikely," and "very unlikely." The journal order was randomized for each participant. At the end of the survey, we asked participants about their gender identity and primary research method, as well as several participant-specific questions and an open-ended question about the survey.
Regarding APSR, the top row of panels reveals that women state that they are less likely to submit their work and be optimistic about publication than men. The middle set of panels shows that the same is true for qualitative scholars. Most importantly, the bottom set of panels demonstrates that the gender perception gap persists even when we control for participants' methodological approach. The only exception is in the case of women quantitative scholars, whose intention to submit is lower than quantitative scholars who are men; however, the difference is only barely insignificant at the o.o5 level (i.e., $p<0.06$ ).

Figure 2 summarizes the results for all journals. We focus on examining gender gaps within the same methodological orientation for each journal. Dots that are to the left (right) of the vertical dotted line indicate that women state that they are less (more) likely than men to submit a manuscript or believe that it will be published in the journal. The top two panels are for quantitative scholars; the bottom two are for qualitative scholars.

\section{Journals with a "Masculinized" Perception Gap}

A few journals exhibit a "masculinized" perception gap, in that men are significantly more likely than women to state that they would submit a manuscript and/or be optimistic about their chances of publication, even within the same broad methodological approach. In addition to APSR, these journals include AJPS and PA. Regarding AJPS and PA, quantitative scholars are much more likely than qualitative scholars to submit their manuscripts and believe that they will be published (see figures C.1 and C.2 in the supplementary materials). Similar to APSR, however, we see gender perception gaps among quantitative scholars. Specifically, gender differences in the likelihood of submission-but not the likelihood of publication-are significant for AJPS. Both differences are significant and slightly larger for $P A$.

\section{Are women more inclined than men to submit their manuscripts to some journals and less inclined to submit to others? Do women perceive the chances of publication differently than men? If so, to what extent can these differences be attributed to different methodological approaches?}

For each likely-unlikely question for each journal, we measure the difference in average scores in three ways: (1) the difference between women and men; (2) the difference between quantitative and qualitative scholars; and (3) the difference between women and men, within each methodological orientation. ${ }^{6}$

\section{RESULTS}

Figure 1 shows these results for APSR; detailed results for all other journals are included in figures C.1 through C.8 in the supplementary materials. Two bars in each panel represent average scores for men versus women or for quantitative versus qualitative scholars. The 95\% confidence intervals are shown in error bars. We also test differences statistically and report the results above the bars. The numbers in parentheses are standard errors. The differences that are statistically significant at the 0.05 level are highlighted in black.

\section{Journals with a "Feminized" Perception Gap}

Views on two journals in our survey, PGI and JPSE, are characterized by gender perception gaps that run in the opposite direction. After controlling for methods, women scholars are more likely than men to submit manuscripts and to be optimistic about their chances of publication. These are journals with a "feminized" perception gap. The journal showing the clearest pattern is $P G I$ (figure 3). Regardless of their methodological orientation, women are more likely to state that they will submit a manuscript and get it published at $P G I$. These effects are large and highly significant. Another journal with a similar pattern is JPSE (see figure C. 3 in the supplementary materials), in which qualitative women scholars are more likely to state that they will submit their work and get it published compared to qualitative men scholars. There is no gender gap among quantitative scholars. 
Figure 1

American Political Science Review
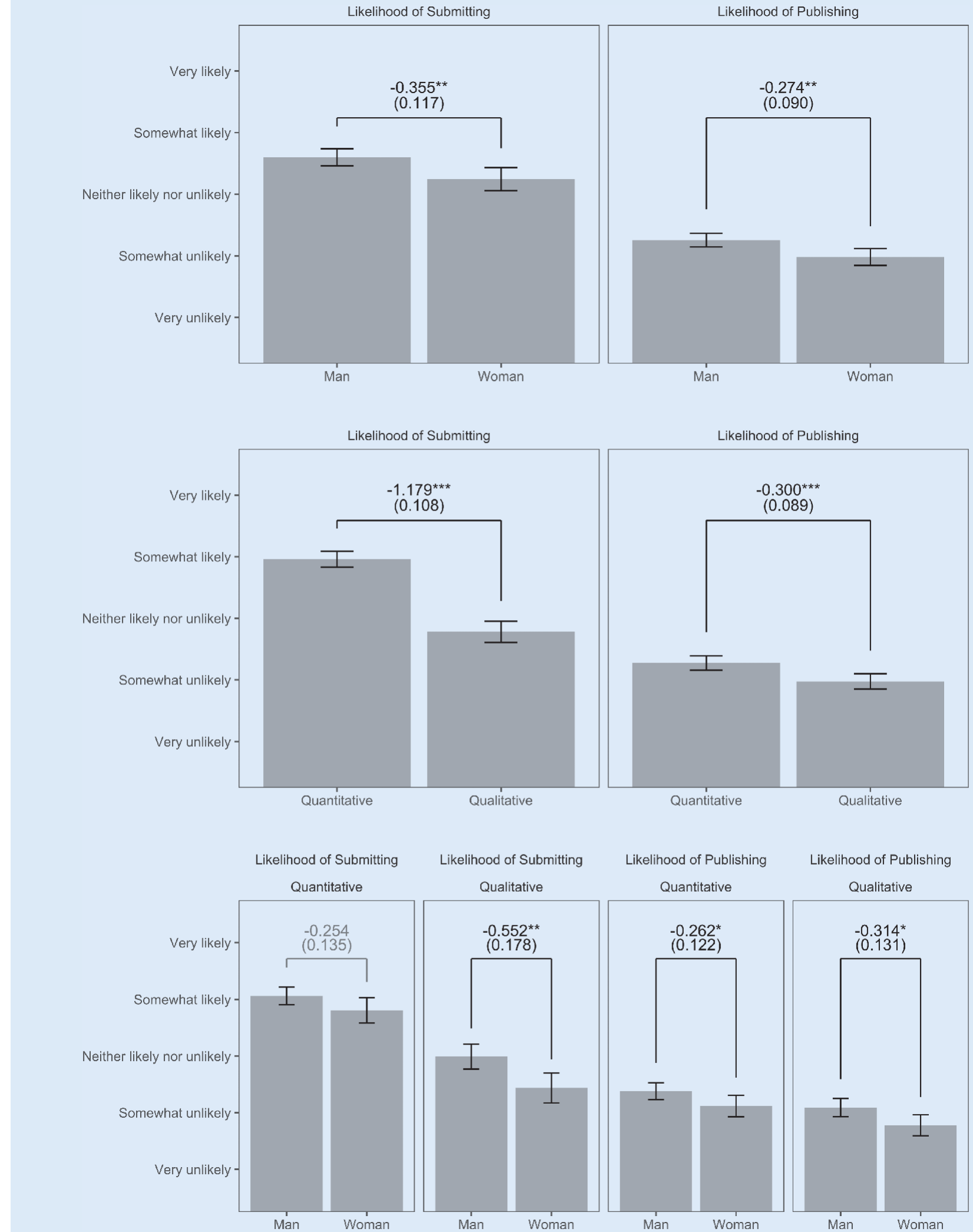

Likelihood of Publishing

Note: The differences that are statistically significant at the 0.05 level are highlighted in black. 


\section{Journals with No Gender Perception Gap}

At most other journals in our survey, no gender perception gap exists among quantitative or qualitative scholars. At CPS, $J O P, P B$, and $P R Q$, however, there is a methods gap: quantitative scholars are significantly more likely to state that they will submit and get published (see figures C.4 through C.7 in

\section{Robustness Tests}

Figure 2 shows the association between participants' gender identity and the outcome variables among quantitative and qualitative scholars. Readers may wonder whether some of the gender perception gaps could be attributable to other factors. As a robustness test, we run our analysis using additional con-

\section{[T] he gender perception gap persists even when we control for participants' methodological approach.}

the supplementary materials). At $I O$, quantitative scholars are significantly more likely than qualitative scholars to state that they will submit their manuscripts (see figure C.8 in the supplementary materials). However, there is no gender perception gap within the methodological approach at any of these journals. By contrast, non-quantitative scholars state that they are more likely to submit and get published in PoP, PT, and Polity (see figures C.9 through C.11 in the supplementary materials). However, for the most part, there is no gender gap when we hold methods constant.?

\section{Figure 2}

\section{Results of Difference-of-Means Tests}

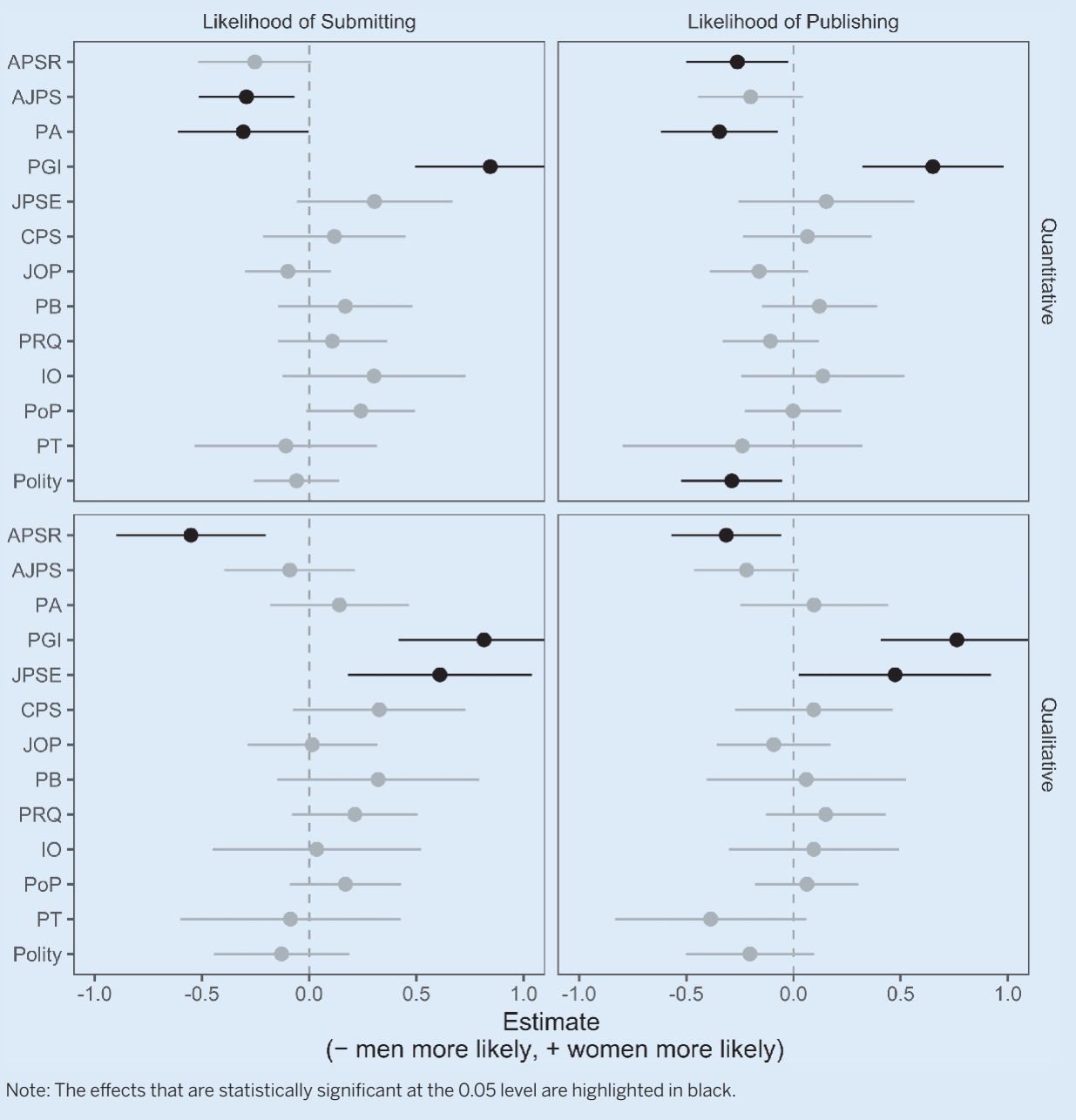

trol variables, including participants' subfield, position, and institution type (see supplementary materials A). We add each categorical variable to regression analysis as a set of dichotomous variables with one category as the baseline. We also include our main variables-each participant's gender identity (i.e., man or woman), methodological approach (i.e., quantitative or not), and their interactions-in the estimation. Results reported in figure C.12 in the supplementary materials demonstrate that our findings remain robust. ${ }^{8}$

\section{DISCUSSION}

These results suggest the existence of gender perception gaps for some but not all journals but do not directly answer two important questions. We discuss them in turn.

\section{What Explains Perception Gaps?}

What underlies the perception gaps of these journals? Several studies argue that gender publication and submission gaps are related to gender gaps in methods. Women are underrepresented at some journals, the argument claims, because these journals emphasize quantitative articles. That is, because women's work tends to be relatively more qualitatively oriented than men's, women prefer to avoid quantitatively-oriented journals and submit their work elsewhere (Breuning and Sanders 2007; Evans and Moulder 2011; Teele and Thelen 2017).

Do men and women differ in their choice of methods? Our survey asked participants about their primary methodological approach. We find that $59 \%$ of women and $57 \%$ of men select some type of quantitative method as their main approach. Figure 4 shows the distribution of methodological approaches by gender among survey participants using the 
Figure 3

Politics, Groups, and Identities
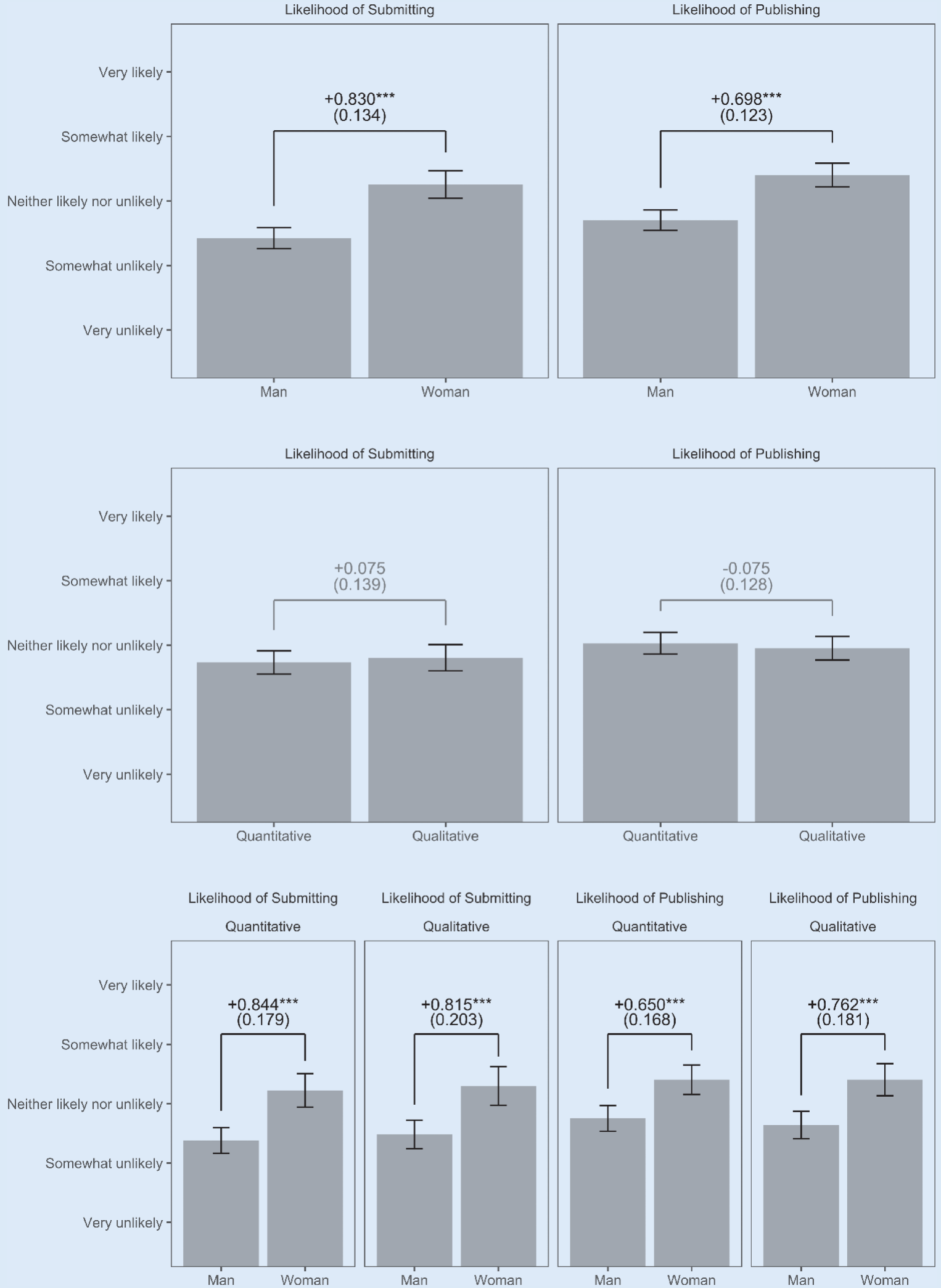

Likelihood of Publishing

Likelihood of Publishing

Quantitative

Qualitative
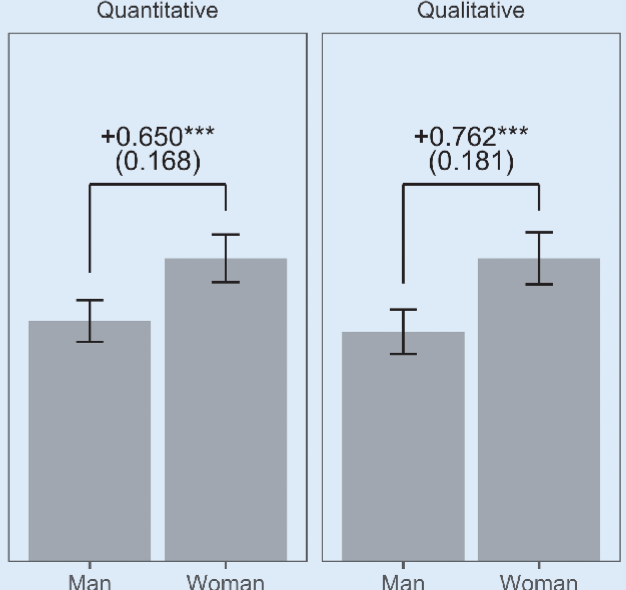

Note: The differences that are statistically significant at the 0.05 level are highlighted in black. 


\section{Figure 4}

\section{Distribution of Methodological Approaches by Gender}

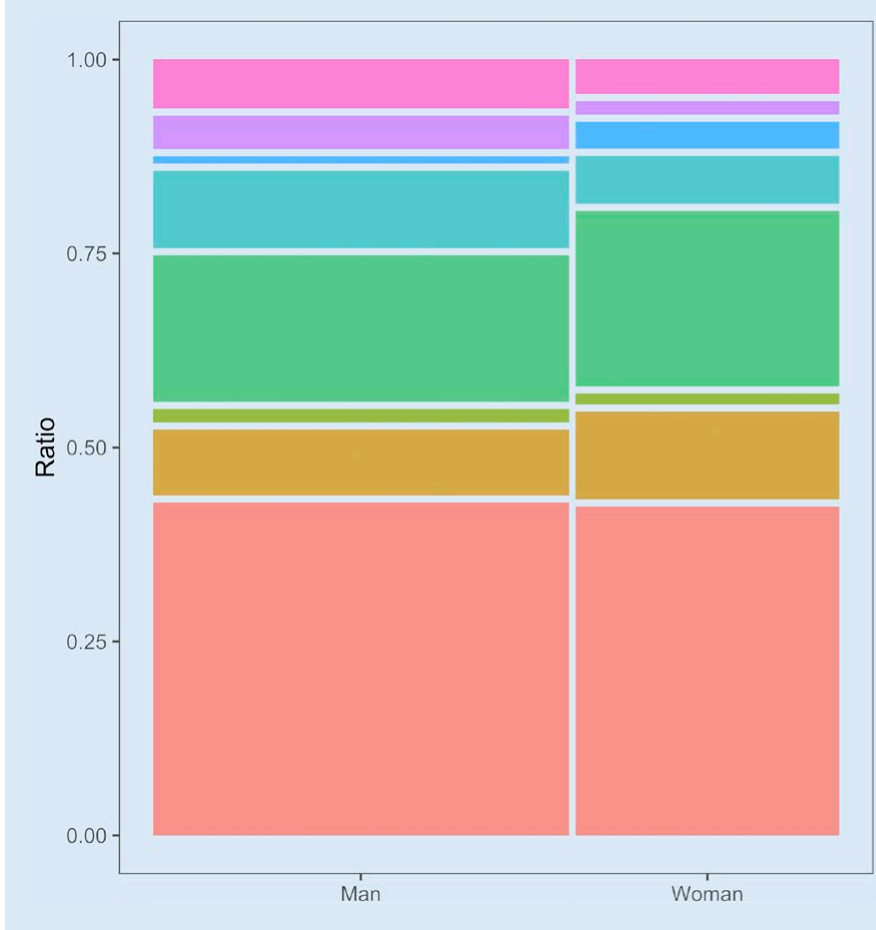

more-refined categories set by the APSA publications committee. ${ }^{9}$ The high share of women who engage in various types of quantitative research makes it unlikely that women's underrepresentation in some quantitatively oriented journals is due exclusively to their choice of method. As demonstrated in our analysis, some of the gender perception gaps persist among scholars within the same methodological orientation. In other words, gender matters even after controlling for methods.

What could be other reasons for the perception gap? Because women tend to be underrepresented among journal editors and editorial boards, women lead editors at journals could serve as role models and send welcoming signals to potential women authors (Topaz and Sen 2016). In our sample, however, the gender identity of the lead editor is not clearly associated with differences between journals with "masculinized" perception gaps (e.g., APSR and AJPS) and those with no gender perception gap (e.g., JOP and CPS). All of these journals had men lead editors at the time our survey was in the field, and three had women lead editors in the not-too-distant past.

Another possible explanation centers on journal prestige and perceived risk associated with submission. Djupe, Smith, and Sokhey (2019) find that women are more likely than men to state that they submit their work to the journal most likely to accept it, whereas men are more likely than women to state that they first submit their work to a top-tier journal. Gender differences in risk aversion thus imply that women initially may be less willing than men to submit their work to journals with high rejection rates..$^{10}$

In our view, gender differences in risk aversion are the likely product of socially conditioned publication strategies. Individual decisions about where to submit, how often-and whether and where to resubmit a paper that has already been rejected-tend to be shaped by interpersonal contacts and information communicated through social networks, as well as habits acquired through

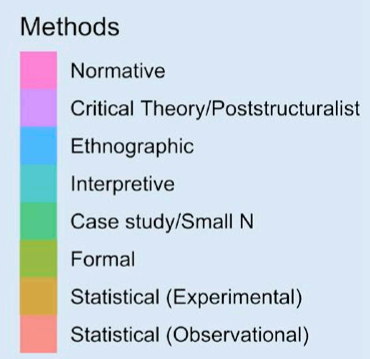

collaborative relationships, which often differ by gender.

For example, Djupe, Smith, and Sokhey (2019) show that men and women are equally likely to collaborate but that men gain many more submissions and publications as a function of collaboration. This pattern suggests that something happens to men in their collaborative networks that bolsters their likelihood to submit papers and to resubmit previously rejected papers. Younger men scholars in highly productive collaborative groups may be more likely to receive encouragement for and to develop early habits of frequent article submission. They also may feel more inoculated against the morale-damaging effects of rejection from top-tier journals.

\section{Do Perception Gaps Explain Submission Gaps?}

Gender publication and submission gaps exist at most journals (Djupe, Smith, and Sokhey 2019; Teele and Thelen 2017), but not all journals have gender perception gaps. At some journals, the gaps align: APSR, for example, has both a publication and a submission gap-women authors comprised an average $23 \%$ to $24 \%$ of authors of published and submitted articles in the 20oos (König and Ropers 2018; Teele and Thelen 2017) -as well as a perception gap that we reveal in this article. The same is likely true at $A J P S$ and $P A$, although we lack data on submissions by gender. By contrast, although the editors of both CPS and $P B$ acknowledge gender submission gaps (Peterson 2018; Samuels 2018), our study does not find any difference, by gender, in the perceived likelihood of submitting to either journal.

As this suggests, differences in attitudes toward journals do not always align with differences in behavior. For some journals, women and men may state that they are equally likely to submit their manuscripts, even though men ultimately submit more papers. In these cases, the gender submission gap may stem from habit rather than gender differences in preferences or aversions to a journal. However, in other cases, men are more likely than women to state that they will submit a manuscript to a journal and actually do so. Whether or not attitudes toward journals align with actual behavior may have implications for strategies to close the gender publication gap, as discussed in the conclusion.

\section{CONCLUSION}

Our analysis generates several important findings about gender perception gaps. First, gender gaps characterize perceptions of some but not all journals. Second, gender gaps run in both directions, with men more favorable to some journals (e.g., APSR) and women to others (e.g., PGI). Third, perception gaps cannot be explained primarily by gender differences in 
methodological orientations. Men and women within quantitative and non-quantitative research communities tend to have different perceptions of some journals in our study-and likely more throughout the discipline. Fourth, although submission gaps are relatively constant across journals, perception gaps are not. In other words, behavior is not always aligned with attitudes.

To promote diversity and inclusion in the profession, journal editors should try to alter the gender composition of the submission pools, which will improve gender balance among published authors as long as review processes remain unbiased. The alignment-or lack thereof-between submission and perception gaps may be consequential for journals' outreach strategies. When gender gaps in submissions are not matched by gender gaps in attitudes toward a journal, editors simply may need to change habits and encourage men or women (depending on the direction of the perception gap) to submit more. When gender gaps in submissions align with gender gaps in perceptions, outreach also may need to focus on changing the substance of journals' reputations. Expectations about potential biases in the types of articles that a journal publishes could affect scholars' decisions to submit (Breuning et al. 2018; Nedal and Nexon 2018). with de-identified data is available at Yusaku Horiuchi's Dataverse (https://doi. org/10.7910/DVN/CIBFU 4 ).

2. Although presented as studies of bias, these observational (i.e., nonexperimental) studies are unable strictly to causally identify the presence or absence of gender bias. To rule out bias, researchers would need to randomly assign men's and women's names to papers to eliminate other confounding factors. Nevertheless, these studies demonstrate that acceptance rates for the five journals are not statistically indistinguishable between men and women, conditional on submission. We thank one anonymous reviewer for insisting on this point.

3. In contrast, another study suggests that the share of women authors overall has grown over time (König and Ropers 2018).

4. We refer to gender differences in answers to these questions as "gender perception gaps" because we believe that scholars' intentions to submit a manuscript to a journal, and the subjective likelihood of getting it published there, are a function of their opinions and impressions of a journal.

5. For further details and discussions of the sample and survey, see supplementary materials A and B.

6. For simplicity, the ordinal response questions are treated as continuous variables. See supplementary materials B for the classification of quantitative and qualitative scholars in our survey.

7. Figure 2 shows that women quantitative scholars state that they are less likely than men to get published at Polity, whereas qualitative scholars overall are more likely to publish in the journal (see figure C.11 in the supplementary materials).

8. We do not report results of this multivariate-regression analysis as our main findings because gender is causally prior to all of these variables added to the analysis. Thus, adding these variables introduces a methodological problem of post-treatment bias. Examining the causal effects of gender as a variable is inherently difficult.

9. See supplementary materials B for a discussion of categories and coding.

\section{[A]lthough submission gaps are relatively constant across journals, perception gaps are not. In other words, behavior is not always aligned with attitudes.}

As Breuning et al. (2018) point out, however, editors can do only so much to influence impressions. Scholars in multiple positions throughout the discipline-advisers, colleagues, and peers-also play an important role in shaping views about what reviewers and journal editors want to publish as well as what type (and whose) work is worth submitting where. Promoting greater gender balance in submission pools requires a collective effort in which we all encourage one another to take risks and to remain resilient when we are rejected. At the same time, politica science should join other scholarly disciplines in the movement to evaluate research primarily by its substance, novelty, and rigor rather than narrower metrics such as journal impact factors and numbers of citations (Heckman and Moktan 2018; Jensenius et al. 2018). ${ }^{11}$

\section{SUPPLEMENTARY MATERIAL}

To view supplementary material for this article, please visit https://doi.org/10.1017/S1049096519001227

\section{NOTES}

1. This article is a product of the American Political Science Association Presidential Task Force on Women's Advancement. We presented an earlier version at the Journal Editors' Breakfast at the 2018 Annual Meeting of the American Political Science Association on September 1, 2018 and at the Society for Scholarly Publishing Annual Meeting on May 30, 2019; at faculty search workshops at the University of New Mexico; and at seminars at the University of Massachusetts, Amherst, and at the University of Oregon. We are grateful for help with the survey from Brittany Ortiz, Betsy Super, and APSA and useful comments from participants at these conferences, workshops, and seminars, as well as Lisa Baldez, Deborah Brooks, John Carey, Katie Clayton, Francesca Jensenius, Frances Rosenbluth, Jane Lawrence Sumner, Julie Lynch, and Dawn Teele. This material is based in part on work supported by the National Science Foundation ADVANCE program under Grant No. 1628471. A replication package
10. It also could be the case that women scholars are more likely to underestimate the quality of their work and therefore are less likely to submit to general journals that often are referred to as "top journals"-in the same way that women candidates are more likely to understate their qualifications for political office (Lawless and Fox 2005).

11. See the San Francisco Declaration on Research Assessment (https://sfdora.org/ read).

\section{REFERENCES}

Box-Steffensmeier, Janet M., Raphael C. Cunha, Roumen A. Varbanov, Yee Shwen Hoh, Margaret L. Knisley, and Mary Alice Holmes. 2015. "Survival Analysis of Faculty Retention and Promotion in the Social Sciences by Gender." PloS One 10 (11): e0143093.

Breuning, Marijke, Benjamin Isaak Gross, Ayal Feinberg, Melissa Martinez, Ramesh Sharma, and John Ishiyama. 2018. "Clearing the Pipeline? Gender and the Review Process at the American Political Science Review." PS: Political Science \& Politics 51 (3): 629-34.

Breuning, Marijke, and Kathryn Sanders. 2007. "Gender and Journal Authorship in Eight Prestigious Political Science Journals." PS: Political Science \& Politics $40(2): 347-51$

Colgan, Jeff. 2017. "Gender Bias in International Relations Graduate Education? New Evidence from Syllabi." PS: Political Science \& Politics 50 (2): 456-6o.

Dion, Michelle L., Jane Lawrence Sumner, and Sara McLaughlin Mitchell. 2018. "Gendered Citation Patterns across Political Science and Social Science Methodology Fields." Political Analysis 26 (3): 312-27.

Djupe, Paul A., Amy Erica Smith, and Anand Edward Sokhey. 2019. "Explaining Gender in the Journals: How Submission Practices Affect Publication Patterns in Political Science." PS: Political Science \& Politics 52 (1): 71-77.

Evans, Heather K., and Ashley Moulder. 2011. "Reflecting on a Decade of Women's Publications in Four Top Political Science Journals." PS: Political Science $\mathcal{E}$ Politics 44 (4): 793-98

Heckman, James J., and Sidharth Moktan. 2018. "Publishing and Promotion in Economics: The Tyranny of the Top Five." NBER Working Paper No. 25093, September

Jensenius, Francesca R., Mala Htun, David J. Samuels, David A. Singer, Adria Lawrence, and Michael Chwe. 2018. "The Benefits and Pitfalls of Google Scholar." PS: Political Science \& Politics 51 (4): 820-24. 
König, Thomas, and Guido Ropers. 2018. "Gender and Editorial Outcomes at the American Political Science Review.” PS: Political Science \& Politics 51 (4): 849-53.

Lawless, Jennifer L., and Richard L. Fox. 2005. It Takes a Candidate: Why Women Don't Run for Office. New York: Cambridge University Press.

Maliniak, Daniel, Ryan Powers, and Barbara F. Walter. 2013. "The Gender Citation Gap in International Relations.” International Organization 67 (4): 889-922.

Nedal, Dani K., and Daniel H. Nexon. 2018. "Gender in the International Studies Quarterly Review Process.” PS: Political Science \& Politics 51 (4): 859-65.

Peterson, David A. M. 2018. "Author Gender and Editorial Outcomes at Political Behavior.” PS: Political Science \& Politics 51 (4): 866-69.
Samuels, David. 2018. "Gender and Editorial Outcomes at Comparative Political Studies.” PS: Political Science \& Politics 51 (4): 854-58.

Teele, Dawn Langan, and Kathleen Thelen. 2017. "Gender in the Journals: Publication Patterns in Political Science.” PS: Political Science \& Politics $50(2): 433-47$.

Topaz, Chad M., and Shilad Sen. 2016. "Gender Representation on Journal Editorial Boards in the Mathematical Sciences." PLoS One 11 (8): e0161357.

Tudor, Carissa L., and Deborah J. Yashar. 2018. "Gender and the Editorial Process: World Politics, 2007-2017.” PS: Political Science \& Politics 51 (4) $870-80$ 